\title{
Caracterizações físico-química e sensorial de estruturados da polpa concentrada de jabuticaba
}

\section{Physical-chemical and sensory characterization of structured of concentrated jabuticaba pulp}

\author{
Larissa Ribas Fonseca1, Naiara Barbosa Carvalho², Pollyanna Amaral Viana ${ }^{2 *}$ (i) \\ ${ }^{1}$ Universidade Estadual de Campinas (UNICAMP), Campinas/SP - Brasil \\ ${ }^{2}$ Universidade Federal de Viçosa (UFV), Florestal/MG - Brasil \\ *Corresponding Author: Pollyanna Amaral Viana, Universidade Federal de Viçosa (UFV), Instituto de Ciências \\ Exatas e Tecnológicas, Campus Florestal, Rodovia LMG 818, km 06, CEP: 35690-000, Florestal/MG - Brasil, \\ e-mail: pollyanna.viana@ufv.br
}

Cite as: Fonseca, L. R., Carvalho, N. B., \& Viana, P. A. (2021). Physical-chemical and sensory characterization of structured of concentrated jabuticaba pulp. Brazilian Journal of Food Technology, 24, e2020115.

https://doi.org/10.1590/1981-6723.11520

\begin{abstract}
Resumo
A jabuticaba é nativa da Mata Atlântica do Brasil, sendo uma das frutas mais cultivadas em pomares domésticos, podendo ser consumida in natura ou industrializada. Pela multiplicidade de usos, apresenta apreciável potencial econômico, mas não tem valor comercial alto por ser perecível. Estruturados da polpa concentrada de jabuticaba foram obtidos empregando-se hidrocoloides, como pectina e gelatina, além de edulcorantes, como maltose, sorbitol, glicose e glicerol, considerados supressores da atividade de água. A polpa de jabuticaba e os estruturados obtidos foram caracterizados quanto ao $\mathrm{pH}$, à acidez titulável, à umidade, a sólidos solúveis totais, teor de cinzas, lipídeos, proteínas, açúcares redutores e não redutores e minerais (sódio e potássio). Quanto à análise sensorial foram realizados testes de aceitação e intenção de compra dos estruturados de jabuticaba, obtendo-se boa aceitação dos avaliadores, apresentando índices elevados de intenção de compra. As formulações F1 (contendo glicose, gelatina e pectina) e F4 (contendo sorbitol, gelatina, pectina e maltose) apresentaram diferenças nas proporç̃̃es de açúcares utilizados, mostrando vantagem em relação às demais formulações, no que diz respeito ao custo para elaboração e ao menor teor de açúcar. Outra vantagem refere-se ao uso de sorbitol, que possui mais poder adoçante comparado à glicose, utilizado na $\mathrm{F} 4$, sendo uma alternativa viável para a substituição da glicose, tornando o estruturado mais saudável por conter menor teor de carboidrato. Assim, como as formulações F1 e F4 foram bem aceitas pelos avaliadores, poderiam ser as mais indicadas para a produção pelas indústrias de alimentos.
\end{abstract}

Palavras-chave: Fruta estruturada; Jabuticaba; Caracterização; Aceitabilidade sensorial.

\begin{abstract}
Jabuticaba is a native fruit of the Brazilian Atlantic Forest, being one of the fruits most cultivated in domestic orchards; it can be consumed in nature or industrialized. Due to the multiplicity of uses, it presents considerable economic potential, but it does not have very high commercial value, because it is perishable. Structured of jabuticaba concentrated pulp was obtained using different hydrocolloids such as pectin and gelatin, as well as
\end{abstract}


sweeteners such as maltose, sorbitol, glucose, and glycerol, used as water activity suppressors. The jabuticaba pulp and the structured ones were characterized as $\mathrm{pH}$, titratable acidity, moisture, total soluble solids, ashes, lipids, proteins, reducing and non-reducing sugar, and mineral content (sodium and potassium). For the sensory analysis, the tests of acceptance and intention of purchase of the structure of jabuticaba were carried out, obtained great acceptance by the evaluators, presenting high indices of purchase intention. The formulations F1 (containing glucose, gelatin, and pectin) and F4 (containing sorbitol, gelatin, pectin, and maltose) showed differences in the proportions of sugars used, which is an advantage in relation to the other formulations with regard to the cost to prepare them and the lower sugar content. Another advantage refers to the use of sorbitol, which has a greater sweetening power compared to glucose, used in F4, being a viable alternative for the replacement of glucose, making the structured healthier because it contains less carbohydrate content. Thus, as the F1 and F4 formulations were well accepted by the evaluators, could be the most suitable for production by the food industries.

Keywords: Structured fruit; Jabuticaba; Characterization; Sensory acceptability.

\section{Introdução}

Além de possuírem grande valor nutritivo, as frutas são consideradas complementos da alimentação básica, o que garante energia, minerais, vitaminas, compostos antioxidantes, entre outros compostos necessários à população (Melo \& Almeida, 2015). Além desse fato e da falta de tempo para o preparo de uma alimentação saudável, a praticidade, o consumo de frutas e a preocupação com a saúde têm sido fatores que aumentaram a comercialização de frutas in natura e seus derivados (Lins, 2010).

Para garantir o aumento do consumo de frutas e uma alimentação saudável, as indústrias de alimentos buscam inovações para facilitar o incremento do consumo por produtos naturais, como polpa estruturada, frutas já prontas para o consumo e reaproveitamento de resíduos que podem ser utilizados para outros fins na cadeia alimentar, como energia, produção de embalagens, entre outros. Assim, entre as novas tecnologias de processamento alimentício, a polpa estruturada, por meio da utilização de hidrocoloides, gera a produção de textura adequada da fruta e aumento do prazo de vida útil desta. Esse processo pode ser empregado para matérias-primas de baixo custo quando in natura e que, após esse tratamento, possuirão valor agregado e preservarão os nutrientes por mais tempo (Carvalho, 2007; Carvalho et al., 2008; Cavalcanti, 2012).

A polpa facilita o transporte, diminui a perda e aumenta a vida de prateleira do produto, porém, quando estruturada, tende a ter mais durabilidade comparada à polpa in natura e ser eficiente quando usada na fabricação de doces e caldas. Para isso, têm sido estudados os hidrocoloides, como alginato, pectina e gelatina, que atuam como agentes de retenção de umidade, facilitam o corte e melhoram a textura da polpa (Grizotto et al., 2005a;Grizotto et al.,2007c; Santos et al., 2016).

Assim, a jabuticaba (Plinia cauliflora) pode ser uma boa escolha para avaliar o processamento de estruturação, sendo uma fruta que pertence à família Myrtaceae, amplamente encontrada no Brasil, principalmente na região Sudeste. Possui forma arredondada, globulosa, de até $3 \mathrm{~cm}$ de diâmetro, casca preta e polpa branca de característica agridoce (Lima et al., 2011). Desse modo, a formação da estruturação de polpa pode aumentar o aproveitamento da fruta, como na fabricação de geleias e sucos, além do consumo in natura dela (Barbosa et al., 2017).

Os estruturados formados pelos métodos tradicionais possuem algumas limitações. Por isso, é necessário conhecer e caracterizar a composição da polpa estruturada e dos hidrocoloides adicionados à fruta ou ao vegetal para melhor compreender seu comportamento na formação do gel e avaliar a possibilidade de utilizálos em sistemas de géis mistos. A tendência do mercado consumidor por produtos mais saudáveis tem incentivado o desenvolvimento de fruta estruturada com mais quantidade de polpa de fruta e quantidade mínima de açúcar (Melo \& Almeida, 2015).

Diante disso, o presente trabalho visa pesquisar os parâmetros do processo para a estruturação da polpa concentrada de jabuticaba, avaliando-se os efeitos das misturas de hidrocoloides sobre as características 
físico-químicas e sensoriais do produto elaborado. Objetiva estabelecer uma polpa estruturada com qualidades desejáveis, como propriedade de gel utilizando glicose, glicerol ou sorbitol como supressor da atividade de água e quantidade mínima possível de sacarose, de modo a promover mais aproveitamento e comercialização das frutas.

\section{Material e métodos}

\subsection{Matéria-prima}

Neste trabalho, foi utilizada a polpa concentrada de jabuticaba, sendo os frutos adquiridos em Florestal (MG). Todos os procedimentos foram realizados seguindo-se as Boas Práticas de Fabricação (BPF). As jabuticabas foram selecionadas e lavadas em água corrente e imersas em solução aquosa de hipoclorito de sódio a $2 \%(\mathrm{v} / \mathrm{v})$ por 20 minutos. Para a elaboração da polpa, os frutos foram previamente macerados, de modo manual, e, posteriormente, despolpados em uma despolpadeira (marca Itametal - modelo compacta com peneira de aço inox com furos de $1 \mathrm{~mm}$ de diâmetro) para retirada das cascas e sementes. A polpa obtida nesse processo teve coloração rosada, levemente viscosa, $\mathrm{pH}$ próximo a 3,5 e teor de sólidos totais em torno de 7,7. Em seguida, foram divididos em três sacos de polietileno contendo cerca de $4 \mathrm{~kg}$ cada um, correspondentes a uma repetição, e estocados à temperatura de $-20^{\circ} \mathrm{C}$ até o momento da utilização. Análises microbiológicas foram realizadas em triplicata. Características como ${ }^{\circ}$ Brix e $\mathrm{pH}$ foram medidas inicialmente, a fim de caracterizarmos a polpa da fruta utilizada, antes e após a realização da estruturação desta.

\subsection{Reagentes}

Gelatina, pectina, glicose, sacarose, maltose, glicerol e sorbitol foram utilizados para estruturação da polpa de jabuticaba e bicarbonato de sódio $\left(\mathrm{NaHCO}_{3}\right)$, para elevar o $\mathrm{pH}$ desta.

\subsection{Estruturação da polpa de fruta}

Para a estruturação da polpa concentrada de jabuticaba, foram testados vários reagentes (glicerol, glicose, sorbitol, hidrocoloides, frutose, maltose e sacarose) e combinações deles, baseando-se nos métodos (aquecimento, agitação, vácuo, refrigeração, secagem, entre outros) da estruturação de outras frutas (açaí, manga, mamão, abacaxi, entre outras), como descritos por estudos realizados por Grizotto et al. (2005b), Grizotto, et al.(2007c) e Oliveira et al. $(2010,2012)$. Para a moldagem da fruta estruturada, utilizaram-se placas de Petri descartáveis e estéreis (0303-8 marca J Prolab). Os estruturados moldados foram mantidos refrigerados a $4{ }^{\circ} \mathrm{C}$, por 24 horas, na geladeira (marca Consul), para sua completa geleificação. Após a refrigeração, os estruturados foram submetidos à secagem em Shaker (MAXQ6000, marca Thermo Scientific), à temperatura de $37^{\circ} \mathrm{C}$, pelo período das 8 às 10 horas. $\mathrm{O}$ tempo de secagem variou devido à formulação do estruturado. $\mathrm{O}$ fluxograma da estruturação é apresentado na Figura 1.

\subsection{Formulações}

Várias formulações com diferentes combinações de hidrocoloides foram testadas, tendo sido selecionadas as que apresentaram gel mais resistente com menos alteração de sabor. As composições das formulações selecionadas constam na Tabela 1. 


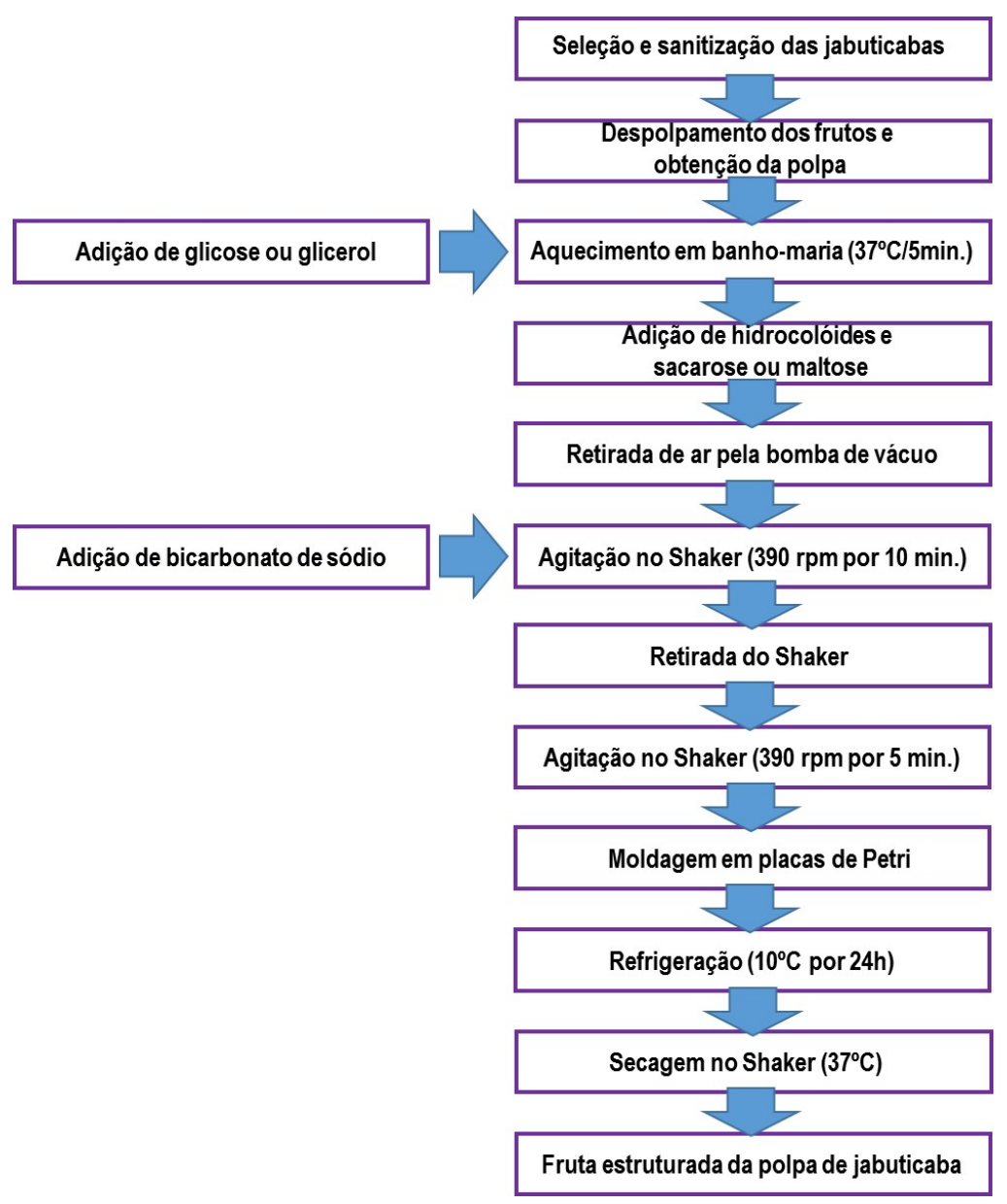

Figura 1. Fluxograma do processamento para produção de fruta estruturada a partir da polpa concentrada de jabuticaba.

Tabela 1. Composição das formulações empregadas nos estudos de estruturação da polpa concentrada de jabuticaba.

\begin{tabular}{|c|c|}
\hline Formulações (F) & Composição \% (p/p) \\
\hline $\mathrm{F} 1$ & $\begin{array}{l}\text { Polpa de jabuticaba }(75 \%) \text {; glicose }(20 \%) \text {; gelatina }(3 \%) \text {; pectina }(2 \%) \text {; bicarbonato de sódio } \\
(0,4 \%) \text {; sacarose até } 50{ }^{\circ} \text { Brix }\end{array}$ \\
\hline F2 & $\begin{array}{l}\text { Polpa de jabuticaba }(78,6 \%) \text {; glicerol }(15 \%) \text {; gelatina }(4 \%) \text {; pectina }(2 \%) \text {; bicarbonato de sódio } \\
(0,4 \%) \text {; maltose até } 50^{\circ} \text { Brix }\end{array}$ \\
\hline $\mathrm{F} 3$ & $\begin{array}{l}\text { Polpa de jabuticaba }(85 \%) \text {; sorbitol }(10 \%) \text {; gelatina }(3 \%) \text {; pectina }(2 \%) \text {; bicarbonato de sódio } \\
(0,4 \%) \text {; sacarose até } 50{ }^{\circ} \text { Brix }\end{array}$ \\
\hline F4 & $\begin{array}{l}\text { Polpa de jabuticaba }(86,6 \%) \text {; sorbitol }(8 \%) \text {; gelatina }(3 \%) \text {; pectina }(2 \%) \text {; bicarbonato de sódio } \\
(0,4 \%) \text {; sacarose e maltose }(1: 2) \text { até } 50^{\circ} \text { Brix }\end{array}$ \\
\hline
\end{tabular}

\subsection{Caracterização físico-química}

As análises físico-químicas foram realizadas no Laboratório de Bioquímica da Universidade Federal de Viçosa (UFV), Campus Florestal, em Florestal (MG). O experimento foi conduzido segundo o Delineamento Inteiramente Casualizado (DIC) para avaliar as características físico-químicas. A polpa e os estruturados obtidos foram caracterizados de acordo com as médias e os desvios-padrão obtidos por meio das análises físico-químicas realizadas, como $\mathrm{pH}$, acidez titulável, sólidos solúveis totais ( ${ }^{\circ}$ Brix), umidade, cinzas, lipídeos, proteínas, potássio, sódio, açúcares redutores e não redutores, conforme descrito pelo Instituto Adolfo Lutz (2008), exceto a análise de proteínas que foi realizada conforme descrito por Layne (1957). 


\subsection{Análise microbiológica}

As análises microbiológicas de bolores e leveduras nos estruturados foram realizadas no Laboratório de Microbiologia de Alimentos da UFV, Campus Florestal, em Florestal (MG), de acordo com a metodologia proposta pela IN n ${ }^{\circ} 62$, de 26 de agosto de 2003, do MAPA. Como os estruturados ainda não possuem uma legislação própria quanto aos requisitos microbiológicos, foram seguidos os padrões para doces e massas estabelecidos pela Resolução da Diretoria Colegiada (RDC) n ${ }^{\circ}$ 12, de 2 de janeiro de 2001 (Brasil, 2001), para avaliarmos os estruturados obtidos quanto a coliformes totais e termotolerantes.

\subsection{Análise sensorial}

Os testes sensoriais foram realizados no Laboratório de Análise Sensorial da UFV, Campus Florestal, em Florestal (MG), para determinar a aceitação e a intenção de compra do produto final por 100 consumidores de frutas, sendo 54 do sexo masculino e 46 do sexo feminino, todos maiores de 18 anos.

Empregou-se o teste de aceitação com escala hedônica ancorada em nove pontos, variando de "gostei extremamente" (escore 9) a "desgostei extremamente" (escore 1), para os participantes expressarem a aceitação em relação à impressão global, à textura, à aparência (cor) e ao sabor, conforme metodologia descrita por Faria e Yotsuyanagi (2002) e Minim (2018). A intenção de compra também foi avaliada utilizando-se a escala hedônica ancorada em cinco pontos, variando de "certamente compraria" (escore 5) a "certamente não compraria" (escore 1).

As quatro formulações (F1, F2, F3 e F4) dos estruturados foram codificadas com números aleatórios de três dígitos e servidas aos consumidores em cabines individuais, sob luz branca, em copos plásticos descartáveis de $50 \mathrm{~mL}$ contendo aproximadamente $10 \mathrm{~g}$ do produto, a temperatura ambiente. Foram apresentadas de forma monádica e aleatória aos avaliadores, tendo sido servida água entre as avaliações.

Este trabalho foi analisado e aprovado pelo Comitê de Ética em Pesquisa com Seres Humanos da UFV, em Viçosa (MG), Brasil, processo $\mathrm{n}^{\circ}$ 48493115.6.0000.5153/2015, estando em conformidade para sua execução e publicação.

\subsection{Análise estatística}

A análise estatística foi realizada no software SAS (Statistical Analysis System), versão 9.1, licenciado para a Universidade Federal de Viçosa. Fez-se o uso da análise de variância (ANOVA) a 5\% em todos os resultados físico-químicos e nos escores dos atributos sensoriais, seguido do Teste de Tukey ( $\alpha=5 \%$ ), para comparação entre as médias dos resultados, quando necessário.

Para as análises microbiológicas, a avaliação dos resultados foi feita comparando-os com os parâmetros preconizados pela legislação.

\section{Resultados e discussão}

\subsection{Caracterização físico-química da polpa e dos estruturados de jabuticaba}

Os resultados obtidos nas análises físico-químicas da polpa e dos estruturados de jabuticaba estão apresentados na Tabela 2.

$\mathrm{O}$ valor do $\mathrm{pH}$ da polpa concentrada de jabuticaba diferiu $(p<0,05)$ dos valores obtidos para os estruturados. As formulações F1 e F3, F1 e F4 não diferiram entre si $(p>0,05)$, porém houve diferença significativa entre as formulações F2 e F3. Observou-se que as maiores médias entre os valores de pH avaliados foram de F3 e F1 foi a menor média da polpa concentrada de jabuticaba, uma vez que foram adicionados às formulações bicarbonato de sódio e outros reagentes (glicose, glicerol e sacarose) que tendem a aumentar o valor do $\mathrm{pH}$ do produto. 
Tabela 2. Caracterização físico-química da polpa e das formulações de estruturados de jabuticaba.

\begin{tabular}{lccccc}
\hline Análises & Polpa & F1 & F2 & F3 & F4 \\
\hline $\mathrm{pH}$ & $3,55 \pm 0,08^{\mathrm{d}}$ & $4,14 \pm 0,06^{\mathrm{ab}}$ & $3,89 \pm 0,07^{\mathrm{c}}$ & $4,28 \pm 0,01^{\mathrm{a}}$ & $4,03 \pm 0,03^{\mathrm{bc}}$ \\
\hline Umidade (\%) & $89,33 \pm 0,37^{\mathrm{a}}$ & $24,92 \pm 0,18^{\mathrm{b}}$ & $32,43 \pm 0,21^{\mathrm{b}}$ & $40,47 \pm 0,14^{\mathrm{c}}$ & $44,39 \pm 0,04^{\mathrm{c}}$ \\
\hline Acidez (\% ácido cítrico) & $0,98 \pm 0,38^{\mathrm{bc}}$ & $0,99 \pm 0,13^{\mathrm{bc}}$ & $1,20 \pm 0,18^{\mathrm{ab}}$ & $0,79 \pm 0,14^{\mathrm{c}}$ & $1,28 \pm 0,13^{\mathrm{a}}$ \\
\hline Sódio (\%) & $0,22 \pm 0,06^{\mathrm{c}}$ & $1,63 \pm 0,07^{\mathrm{a}}$ & $1,75 \pm 0,01^{\mathrm{a}}$ & $1,70 \pm 0,03^{\mathrm{a}}$ & $0,99 \pm 0,11^{\mathrm{b}}$ \\
\hline Potássio (\%) & $0,52 \pm 0,18^{\mathrm{a}}$ & $0,78 \pm 0,21^{\mathrm{a}}$ & $0,62 \pm 0,14^{\mathrm{a}}$ & $0,55 \pm 0,04^{\mathrm{a}}$ & $0,87 \pm 0,11^{\mathrm{a}}$ \\
\hline Proteínas (\%) & $1,26 \pm 0,13^{\mathrm{a}}$ & $0,96 \pm 0,18^{\mathrm{b}}$ & $0,88 \pm 0,14^{\mathrm{c}}$ & $0,77 \pm 0,00^{\mathrm{d}}$ & $0,77 \pm 0,05^{\mathrm{d}}$ \\
\hline Cinzas (\%) & $2,73 \pm 0,07^{\mathrm{a}}$ & $2,86 \pm 0,01^{\mathrm{a}}$ & $2,84 \pm 0,03^{\mathrm{a}}$ & $2,99 \pm 0,36^{\mathrm{a}}$ & $2,13 \pm 0,42^{\mathrm{a}}$ \\
\hline${ }^{\circ}$ Brix (\%) & $7,73 \pm 0,21^{\mathrm{b}}$ & $50,00 \pm 0,00^{\mathrm{a}}$ & $50,00 \pm 0,00^{\mathrm{a}}$ & $50,00 \pm 0,00^{\mathrm{a}}$ & $50,00 \pm 0,00^{\mathrm{a}}$ \\
\hline Açúcares redutores (\%) & $4,85 \pm 0,18^{\mathrm{c}}$ & $18,77 \pm 0,14^{\mathrm{b}}$ & $20,04 \pm 0,04^{\mathrm{a}}$ & $18,97 \pm 0,13^{\mathrm{b}}$ & $18,98 \pm 0,06^{\mathrm{b}}$ \\
\hline Açúcares não redutores (\%) & $3,00 \pm 0,01^{\mathrm{b}}$ & $4,33 \pm 0,03^{\mathrm{b}}$ & $16,81 \pm 0,82^{\mathrm{a}}$ & $18,14 \pm 0,42^{\mathrm{a}}$ & $17,91 \pm 0,04^{\mathrm{a}}$ \\
\hline Lipídeos (\%) & $0,19 \pm 0,14^{\mathrm{a}}$ & $0,11 \pm 0,04^{\mathrm{a}}$ & $0,15 \pm 0,96^{\mathrm{a}}$ & $0,12 \pm 0,59^{\mathrm{a}}$ & $0,10 \pm 0,02^{\mathrm{a}}$ \\
\hline
\end{tabular}

Os valores representam a média de três repetições \pm desvio-padrão. Letras iguais na mesma linha indicam não haver diferença significativa para $p<0,05$.

Mouquet et al. (1997) estudaram o efeito do tempo nas características dos estruturados pela cinética avaliando a geleificação de polpas de maracujá texturizadas. Estudos realizados por Soares et al. (2001) e Rosa et al. (2015) mostraram valores para o $\mathrm{pH}$ da polpa de acerola próximos ao encontrado no presente trabalho devido à acidez e ao alto teor de água. Estudos realizados com polpa do Noni (Morinda citrifolia) encontraram o valor de $\mathrm{pH}$ maior $(4,25)$ do que o presente estudo (Correira et al., 2011).

Em relação à análise de umidade, as quatro formulações de estruturados da polpa de jabuticaba diferiramse $(p<0,05)$, como pode ser observado na Tabela 2. As formulações F1 e F2 não obtiveram diferenças significativas entre si, porém diferiram das formulações F3 e F4. Uma possível justificativa para isso é a utilização de diferentes hidrocoloides. O sorbitol possui características distintas dos demais utilizados neste estudo, como alto poder adoçante e umectante e mais viscosidade, o que pode ter facilitado sua maior interação com a água presente na polpa, deixando as formulações F3 e F4 com mais teor de umidade comparadas a F1 e F2. Todas as formulações diferiram $(p<0,05)$ da polpa. Como observado na Tabela 2, a maior média entre os valores de umidade foi a da polpa (89,33\%) comparada à das formulações (25\% a 45\%). Os valores de umidade dos estruturados foram menores do que o da polpa, pois foram submetidos ao processo de secagem, o que pode ter influenciado o baixo valor percentual encontrado nas formulações avaliadas (Santos et al., 2016). O baixo valor de umidade é importante para garantir a conservação e a integridade do estruturado obtido.

Comparando-se os resultados encontrados com os de estudos realizados por outros autores, percebe-se que os valores determinados para umidade da polpa concentrada de jabuticaba neste trabalho se encontram próximos aos valores determinados por Gonsalves et al. (2014) e Soares et al. (2001), os quais encontraram $86,56 \%$ e $89,80 \%$, respectivamente. Oliveira et al. (2010) encontraram valores de umidade entre $25,33 \%$ e $26,50 \%$ para estruturados, sendo próximos do obtido para a F1 (Tabela 2).

$\mathrm{Na}$ análise de acidez, a F4 diferiu $(p<0,05)$ das formulações F1, F3 e da polpa e não diferiu $(p>0,05)$ da F2. Observa-se maior índice de acidez nas formulações F4 e F2 (1,20\% e 1,28\%, respectivamente) e presença de maltose, não encontrada nas demais.

Gonsalves et al. (2014) encontraram um índice de acidez entre $0,98 \%$ e 1,22\% para a polpa de jabuticaba utilizada para a fabricação de iogurte, valores próximos aos encontrados no presente trabalho. Oliveira et al. 
(2012) verificaram para a polpa de abacaxi da variedade Pérola valor inferior a $0,57 \%$, devido à grande presença de ácidos cítrico e málico.

$\mathrm{Na}$ análise de sódio, todas as formulações diferiram $(p<0,05)$ da polpa e as formulações $\mathrm{F} 1, \mathrm{~F} 2$ e F3 não diferiram $(p>0,05)$ entre si, mas diferiram $(p<0,05)$ da F4. Os resultados foram de acordo com o esperado, pois a polpa possui baixo ou nenhum teor de sódio, e nas formulações em teste, foi adicionado bicarbonato de sódio para ajustar o índice de acidez delas.

Em relação à análise de potássio, percebeu-se que a polpa e as formulações analisadas não diferiram entre si $(p>0,05)$. Esse resultado se deve à presença de potássio na composição da fruta (jabuticaba) analisada em todos os tratamentos.

Em relação aos resultados referentes às análises de proteínas, F3 e F4 não diferiram entre si $(p>0,05)$, porém diferiram $(p<0,05)$ de F1, F2 e da polpa. Os valores encontrados para proteínas da polpa de jabuticaba nesse trabalho foram maiores que o padrão encontrado por Soares et al. (2001), ou seja, 0,21\%. Porém, encontram-se próximos aos valores determinados por Santo (2014), ou seja, entre 0,70\% e 1,00\%. F1 e F2 apresentaram teor de proteínas mais alto que os demais estruturados pela adição de sorbitol nas formulações F3 e F4, respectivamente (Oliveira et al., 2010).

Quanto à análise de cinzas, os estruturados e a polpa não diferiram entre si $(p>0,05)$. O teor de cinzas da polpa de jabuticaba se encontra próximo aos valores encontrados por Lima (2009), em estudos com jabuticabas variedades Paulista $(2,90 \pm 0,11)$ e Sabará $(2,71 \pm 0,19)$. Isso mostra que a jabuticaba, entre suas características, é rica em sais minerais, pois as cinzas representam a composição inorgânica de um alimento e são importantes para nosso organismo, principalmente no auxílio da atividade das enzimas.

Em relação à análise de sólidos solúveis, os estruturados apresentaram o mesmo valor $(p>0,05)$, visto que lhes foram adicionados sacarose, maltose e outros sólidos solúveis até alcançar $50^{\circ} \mathrm{Brix}$, valores maiores $(p<0,05)$ que o da polpa. Gonsalves et al. (2014) determinaram para a polpa de jabuticaba valores de ${ }^{\circ}$ Brix de 7,0 a 12,0, valores próximos à polpa concentrada de jabuticaba do presente trabalho.

Em relação ao teor de açúcares redutores, F1, F3 e F4 obtiveram valores semelhantes $(p>0,05)$, porém todos os estruturados diferiram $(p<0,05)$ da polpa e F2 diferiu $(p<0,05)$ de ambos (polpa e demais formulações). Esse fato já era esperado devido à adição de açúcares redutores na produção dos estruturados, sendo a maior média entre os valores de açúcares redutores analisados da F2 e a menor média a da polpa (Tabela 2). Como os açúcares redutores do fruto dependem de seu estágio de maturação, provavelmente as jabuticabas utilizadas não estavam todas em seu estágio de maturação completo, o que explica a grande diferença entre os estruturados e a polpa concentrada de jabuticaba. Silva et al. (2009) encontraram valores menores $(5,11 \%$ a $7,02 \%)$ de açúcares redutores para estruturados das polpas de cajá e goiaba, provavelmente pelo fato de não terem sido adicionadas glicose nem maltose às formulações.

Em relação à análise de açúcares não redutores, $\mathrm{F} 1$ e a polpa obtiveram teores que não diferiram entre si $(p>0,05)$, mas diferiram $(p<0,05)$ das formulações F2, F3 e F4. Esse resultado já era esperado pelo fato de a polpa conter pouco ou nenhum açúcar não redutor em sua composição e ser adicionada sacarose, que é um açúcar não redutor nas formulações dos estruturados.

$\mathrm{Na}$ análise de lipídeos, observa-se que as amostras (polpa e formulações) possuem teor baixo (média de $0,13 \%)$, não diferindo entre si $(p>0,05)$ quanto a esse parâmetro. Com base nos estudos de Teixeira (2011), observa-se que, de modo geral, as frutas não possuem valores significativos de lipídeos, sendo o teor na polpa da jabuticaba da variedade Sabará de 0,67\%. Conforme Elias et al. (2008), ao avaliarem caqui desidratado, encontraram teor de lipídeos de $0,40 \%$. Esses valores podem variar de acordo com a característica biológica de cada fruta, o estágio de maturação, variações climáticas e formas de processamento. 


\subsection{Análise microbiológica}

Os resultados experimentais para os estruturados da polpa concentrada de jabuticaba foram negativos para a presença de coliformes termotolerantes, coliformes totais e fungos. De acordo com a RDC n ${ }^{\circ} 12$, de 2 de janeiro de 2001, da Agência Nacional de Vigilância Sanitária (Anvisa), é estabelecido que purês e doces em pasta ou massa e similares, incluindo geleias, não comercialmente estéreis devem apresentar contagem máxima para amostra indicativa de $10^{4}$ bolores e leveduras/g de amostra. Quando avaliada a qualidade microbiológica dos estruturados, observou-se que estes se mantiveram microbiologicamente estáveis em todos os tratamentos, visto que, no período estudado, não foi observado nenhum crescimento microbiano, estando de acordo com a legislação.

Uma vez que as amostras se encontraram próprias para o consumo humano, as mesmas foram submetidas à análise sensorial.

\subsection{Avaliação sensorial}

Na Tabela 3 são apresentadas as médias de aceitação em relação a atributos sensoriais, impressão global, textura, aparência (cor), sabor e intenção de compra atribuídas, pelos cem avaliadores, às quatro formulações de estruturado da polpa de jabuticaba.

Tabela 3. Escores médios dos atributos sensoriais das formulações de estruturado da polpa concentrada de jabuticaba.

\begin{tabular}{lcccc}
\hline \multirow{2}{*}{ Atributos sensoriais } & $\mathbf{F 1}$ & $\mathbf{F 2}$ & $\mathbf{F 3}$ & Formulações \\
\cline { 2 - 5 } & $7,12 \pm 1,22$ & $6,92 \pm 1,37$ & $6,87 \pm 1,11$ & $7,23 \pm 1,93$ \\
\hline Impressão global & $6,94 \pm 2,16$ & $6,60 \pm 2,01$ & $6,91 \pm 1,83$ & $7,02 \pm 2,19$ \\
\hline Aparência (cor) & $7,25 \pm 1,43$ & $6,89 \pm 1,91$ & $6,83 \pm 1,07$ & $7,15 \pm 1,22$ \\
\hline Sabor & $6,91 \pm 0,94$ & $6,87 \pm 0,97$ & $6,55 \pm 1,21$ & $6,83 \pm 1,17$ \\
\hline Textura & $3,82 \pm 1,55$ & $3,49 \pm 1,73$ & $3,51 \pm 0,92$ & $3,71 \pm 1,34$ \\
\hline Intenção de compra & &
\end{tabular}

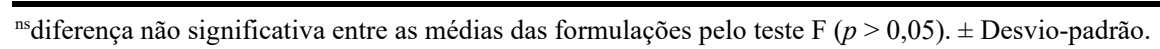

Verificou-se que não houve diferença $(p>0,05)$, entre as diferentes formulações, quanto aos atributos de aceitação e à intenção de compra avaliados (Tabela 3). De modo geral, percebeu-se que as quatro formulações de estruturados da polpa concentrada de jabuticaba foram bem aceitas para todos os atributos avaliados, com médias variando de 6,55 a 7,25, valores situados entre os termos hedônicos "gostei ligeiramente" e "gostei muito".

Quanto à intenção de compra do produto, as quatro formulações obtiveram resultados com médias variando de 3,49 a 3,82, situados entre os termos hedônicos "não compraria" e "provavelmente compraria", reforçando a aceitação dos estruturados obtidos com a polpa concentrada de jabuticaba.

A combinação de pectina e gelatina nas quatro formulações produziu géis mais firmes e a presença de glicose e sorbitol nas formulações F1 e F4, respectivamente, foi eficiente como adoçantes e supressores de água.

Carvalho et al. (2011) e Santos \& Costa (2015), estudaram a combinação de pectina, gelatina e alginato de sódio sobre as características de gel de fruta estruturada a partir de mix de polpa de cajá e mamão, por meio da metodologia de superfície de resposta, e verificaram que somente o aumento da concentração de gelatina afetou a firmeza do produto final. Silva et al. (2009) estudaram a estruturação de frutas utilizando, em suas formulações, diferentes porcentagens de polpas ( $40 \%$ e $60 \%)$ de cajá e goiaba, $10 \%$ de glicerol, $1 \%$ de alginato, $3 \%$ de pectina, $5 \%$ de gelatina, $0,8 \%$ de fosfato de cálcio e sacarose até $60{ }^{\circ}$ Brix. Pela análise 
sensorial, as três formulações de estruturados obtidas mostraram-se bem aceitas para todos os atributos avaliados (impressão global, aparência, aroma, textura e sabor), com notas variando de 7,65 a 8,17, valores que representam "gostei moderadamente" e "gostei muitíssimo", respectivamente. Apenas para o atributo sabor, foi detectada diferença estatística, pelo Teste de Tukey $(p \leq 0,05)$, entre as formulações, tendo F3 média superior às demais, indicando mais aceitação para estruturados com maior teor de cajá (60\%).

Deste modo, observamos a importância dos estudos das polpas estruturadas que vêm sendo avaliadas sobre diferentes formulações e combinações de frutas, como estudos de mix de polpas de umbu com melão ou romã (Jesus et al., 2016) e manga com caju (Leal et al., 2019), e também a avaliação do efeito da concentração dos hidrocoloides e suas variedades, como alginato, pectina, gelatina (Jesus et al., 2016; Luciana et al., 2017) e goma gelana (Bastos et al., 2016; Costa et al., 2019), visando ao aumento da comercialização e ao tempo de vida útil das polpas de frutas.

Embora as formulações de estruturados da polpa concentrada de jabuticaba não tenham apresentado diferença entre si $(p>0,05)$ em relação aos atributos de aceitação e intenção de compra, observa-se que as formulações F1 (75\% de polpa de jabuticaba; $20 \%$ de glicose; $3 \%$ de gelatina; $2 \%$ de pectina; $0,4 \%$ de bicarbonato de sódio; sacarose até $50{ }^{\circ}$ Brix) e F4 ( $85 \%$ de polpa de jabuticaba; $8 \%$ de sorbitol; $3 \%$ de gelatina; $2 \%$ de pectina; $0,4 \%$ de bicarbonato de sódio; sacarose e maltose na proporção $1: 2$ até $50{ }^{\circ}$ Brix) apresentaram diferenças nas proporções de açúcares utilizados, tendo mostrado vantagens em relação às demais formulações, no que diz respeito ao custo para elaboração delas e ao menor teor de açúcar. Outra vantagem refere-se ao uso de sorbitol que possui maior poder adoçante comparado à glicose, utilizado na F4, sendo uma alternativa viável para a substituição da glicose, tornando o estruturado mais saudável por conter menor teor de carboidrato. Assim, como as formulações F1 e F4 foram bem aceitas pelos avaliadores, poderiam ser as mais indicadas para produção pelas indústrias de alimentos.

\section{Conclusão}

Foi possível um processo de produção de fruta estruturada com elevada porcentagem de polpa concentrada de jabuticaba. Portanto, sensorialmente, os estruturados obtidos possuem um potencial de consumo na forma em que foram apresentados, sendo considerados produtos saudáveis. Como as formulações F1 e F4 foram bem aceitas, esses produtos poderiam ser comercializados pelas indústrias alimentícias com apelo de conveniência e praticidade, além de aumentar a vida útil em relação à polpa in natura, tendo a possibilidade de garantir um valor nutricional significativo.

\section{Agradecimentos}

Os autores agradecem aos avaliadores que participaram da análise sensorial e à UFV a infraestrutura.

\section{Referências}

Barbosa, P. S., Andrade, E. S., Jesus, J. H., Brondani, F. M. M., \& Vieira, R. (2017). Análise e quantificação do teor alcoólico do fermentado artesanal de jabuticaba. Revista Científica da Faculdade de Educação e Meio Ambiente, 8(1), 16-32. http://dx.doi.org/10.31072/rcf.v8i1.458

Bastos, J. S., Martinez, E. A., \& Souza, S. M. A. (2016). Características físico-químicas da polpa de umbu (Spondias tuberosa Arruda Câmara) comercial: Efeito da concentração. Journal of Bioenergy and Food Science, 3(1), 11-16. http://dx.doi.org/10.18067/jbfs.v3i1.48

Brasil. Agência Nacional de Vigilância Sanitária. (2001, janeiro 10). Regulamento técnico sobre padrões microbiológicos para alimentos (Resolução de Diretoria Colegiada (RDC) n¹2, de 2 de janeiro de 2001). Diário Oficial [da] República Federativa do Brasil (p. 48), Brasília.

Carvalho, A. V. (2007). Otimização dos parâmetros tecnológicos para a produção de frutas estruturadas de frutas funcionais a partir de polpa de açaí e "mix" de taperebá com mamão. Belém: Embrapa Amazônia Oriental, p. 52.

Carvalho, A. V., Mattietto, A., Assis, G. T., \& Lourenço, L. F. H. (2011). Avaliação do efeito da combinação de pectina, gelatina e alginato de sódio sobre as características de gel de fruta estruturada a partir de "mix" de polpa de cajá e mamão, por meio da metodologia de superfície de resposta. Acta Amazonica, 41(2), 267-274. http://dx.doi.org/10.1590/S0044-59672011000200011 
Carvalho, A. V., Mattietto, R. A., \& Vasconcelos, M. A. M. (2008). Aproveitamento da casca do bacuri para fabricação de um novo produto (Comunicado Técnico). Belém: EMBRAPA.

Cavalcanti, D. T. B. (2012). Desenvolvimento de fruta estruturada simples e mista com ciriguela e acerola (Dissertação de mestrado). Universidade Federal Rural de Pernambuco, Recife.

Correira, A. A. S., Gonzaga, M. L. C., Aquino, A. C., Souza, P. H. M., Figueiredo, R. W., \& Maia, G. A. (2011). Caracterização química e físico-química da polpa do noni (Morinda citrifolia) cultivado no estado do ceara. Alimentos e Nutrição, 22(4), 609.

Costa, J. N., Nascimento, L. G. L., Leal, A. R., Mata, P., Alves, C. A. N., Filho, A. A. L. A., \& Sousa, P. H. M. (2019). Efeito da concentração de hidocoloides nos compostos bioativos, bioacessibilidade e textura instrumental de goiaba (Psidium guajava L.) estruturada. Research Society and Development, 53(9), 1689-1699.

Elias, N. F., Berbert, P. A., Molina, M. A. B., Viana, A. P., Dionello, R. G., \& Queiroz, V. A. V. (2008). Avaliação nutricional e sensorial de caqui submetido à desidratação osmótica e secagem por convecção. Food Science and Technology, 28(2), 322328. http://dx.doi.org/10.1590/S0101-20612008000200009

Faria, E. Z., \& Yotsuyanagi, K. (2002). Técnicas de análise sensorial (1. ed., 116 p.). Campinas: ITAL.

Gonsalves, R. T., Cavenaghi, A. D., Maldonado, C. A. B., Arévalo-Pinedo, A., Salles-Arévalo, D., \& Pinedo, R. A. (2014). Caracteristicas fisicas e químicas do iogurte funcional enriquecido com geleia e fibra de casca de jabuticaba (Myrciaria jaboticaba (Vell.) Berg.). In Anais do XII Congresso Internacional do Leite (pp. 3-5). Porto Velho: Embrapa Gado de Leite. Grizotto, R. K., Aguirre, J. M., \& Menezes, H. C. (2005a). Frutas estruturadas de umidade intermediária obtidas de polpas concentradas de abacaxi, manga e mamão. Food Science and Technology, 25(4), 691-697. http://dx.doi.org/10.1590/S010120612005000400011

Grizotto, R. K., Bruns, R. E., Aguirre, J. M., \& Batista, G. (2005b). Otimização via metodologia de superfície de respostas dos parâmetros tecnológicos para produção de fruta estruturada e desidratada a partir de polpa concentrada de mamão. Food Science and Technology, 25(1), 158-164. http://dx.doi.org/10.1590/S0101-20612005000100026

Grizotto, R. K., Bruns, R. E., De Aguirre, J. M., \& De Menezes, H. C. (2007c). Technological aspects for restructuring concentrated pineapple pulp. Lebensmittel-Wissenschaft + Technologie, 40(5), 759-765. http://dx.doi.org/10.1016/j.lwt.2006.05.002

Instituto Adolfo Lutz - IAL. (2008). Normas analíticas do Instituto Adolfo Lutz: Métodos físico-químicos para análise de alimentos (4. ed.). São Paulo: IAL.

Jesus, G. F., Bastos, J. S., Oliveira, N. A., Anjos, M. B., Santos, J. C. R., Souza, S. M. A., \& Martinez, E. A. (2016). Estudos preliminares na formulação de estruturados de mix de polpa de frutas. Revista do Congresso Sul Brasileiro de Engenharia de Alimentos, 1, 1-10.

Layne, E. (1957). Spectrophotometric and turbidimetric methods of measuring proteins. In S. P. Colowick \& N. O. Kaplan (Eds.), Methods in enzymology (Vol. 3, pp. 447-454). New York: Academic Press. http://dx.doi.org/10.1016/S0076-6879(57)03413-8.

Leal, A. R., Costa, J. N., Vieira, J. M. M., Araújo Filho, A. A. L., \& Sousa, P. H. M. (2019). Manga com caju estruturados: Influência do mel e goma gelana nas características físico-químicas e sensoriais. Research Society and Development, 53(9), 1689-1699.

Lima, A. J. B. (2009). Caracterização e atividade antioxidante da jabuticaba (Myrciaria cauliflora (Mart) O. Berg] (Tese de doutorado). Universidade Federal de Lavras, Lavras.

Lima, A. J. B., Corrêa, A. D., Dantas-Barros, A. M., Nelson, D. L., \& Amorim, A. C. L. (2011). Sugars, organic acids, minerals and lipids in jabuticaba. Revista Brasileira de Fruticultura, 33(2), 540-550. http://dx.doi.org/10.1590/S0100-29452011000200026

Lins, A. C. A. (2010). Desenvolvimento de fruta estruturada com umidade intermediária obtida de polpas concentradas de três genótipos de cajazeira (Spondiasmombin L.) (Dissertação de mestrado). Universidade Federal Rural de Pernambuco, Recife.

Luciana, M., Melo, A., \& Batista, A. M. (2017). Estruturados de cajá-manga (Spondias dulcis) com diferentes hidrocoloides. Enciclopédia Biosfera, 14(25), 530-543.

Melo, B., \& Almeida, M. S. (2015). Valor nutricional das frutas. Uberlândia: UFU. Retrieved in 2019, September 18, from http://www.fruticultura.iciag.ufu.br/nutricao.htm

Minim, V. P. R. (2018). Análise sensorial estudos com os consumidores (4. ed.). Viçosa: UFV.

Mouquet, C., Aymard, C., Guilbert, S., Cuvelier, G., \& Launay, B. (1997). Influence of initial pH on gelation kinetics of texturized passion fruit pulps. Lebensmittel-Wissenschaft + Technologie, 30(2), 129-134. http://dx.doi.org/10.1006/fstl.1996.0143

Oliveira, J. A. R., Carvalho, A. V., Martins, L. H. S., \& Moreira, D. K. T. (2012). Elaboração e caracterização físico-química e sensorial de estruturados de polpa concentrada de abacaxi. Alimentos e Nutrição, 23, 23-31.

Oliveira, J. A. R., Carvalho, A. V., Martins, L. H. S., \& Moreira, D. K. T. (2010). Elaboração e caracterização de estruturado obtido de polpa concentrada de cupuaçú. Ciências Agrárias, 53(2), 164-170. http://dx.doi.org/10.4322/rca.2011.023

Rosa, A., Paiva, C., \& Araújo, F. G. (2015). Caracterização das propriedades físico-químicas da casca e da polpa de jabuticaba. In Anais do IV Congresso Estadual de Iniciação Científica do IF Goiano (p. 82). Morrinhos: IF Goiano.

Santo, T. (2014). Efeito da adição de extrato de casca de jabuticaba nas características físico-químicas e sensoriais de queijo Petit Suisse (Dissertação de mestrado). Universidade Federal do Espírito Santo, Alegre.

Santos, J. C. R., Anjos, M. B., Jesus, G. F., Bastos, J. S., Oliveira, N. A., Souza, S. M. A., \& Martínez, E. A. (2016). Ensaios preliminares para produção de estruturados com acerola e ciriguela. Revista CSBEA, 2(1), 1-8.

Santos, L., \& Costa, R. (2015). Avaliação de hidrocoloides para elaboração de estruturados de cajá-manga. Instituto Federal de Educação, Ciência e Tecnologia. 
Silva, P. A., Carvalho, A. V., \& Pinto, C. A. (2009). Elaboração e caracterização de fruta estruturada mista de goiaba e cajá Revista de Ciências Agrárias, (51), 99-113.

Soares, E. C., Oliveira, G. S. F., Maia, G. A., Monteiro, J. C. S., Silva Junior, A., \& Souza Filho, M. S. (2001). Desidratação da polpa de acerola (Malpighia e marginata D.C.) pelo processo "FOAM-MAT". Food Science and Technology, 21(2), 164-170. http://dx.doi.org/10.1590/S0101-20612001000200008

Teixeira, N. C. (2011). Desenvolvimento, caracterização físico-química e avaliação sensorial de suco de jabuticaba (Myrciaria jaboticaba (Vell) Berg) (Dissertação de mestrado). Programa de Pós-graduação em Ciência de Alimentos, Universidade Federal de Minas Gerais, Belo Horizonte.

Funding: Ministério da Ciência, Tecnologia e Inovação > Conselho Nacional de Desenvolvimento Científico e Tecnológico. 